\title{
Response Burden in Official Business Surveys: Measurement and Reduction Practices of National Statistical Institutes
}

\author{
Mojca Bavdaž ${ }^{1}$, Deirdre Giesen ${ }^{2}$, Simona Korenjak Černe ${ }^{3}$, Tora Löfgren ${ }^{4}$, and \\ Virginie Raymond-Blaess 5
}

\begin{abstract}
Response burden in business surveys has long been a concern for National Statistical Institutes (NSIs) for three types of reasons: political reasons, because response burden is part of the total administrative burden governments impose on businesses; methodological reasons, because an excessive response burden may reduce data quality and increase data-collection costs; and strategic reasons, because it affects relations between the NSIs and the business community. This article investigates NSI practices concerning business response burden measurement and reduction actions based on a survey of 41 NSIs from 39 countries. Most NSIs monitor at least some burden aspects and have implemented some actions to reduce burden, but large differences exist between NSIs' methodologies for burden measurement and actions taken to reduce burden. Future research should find ways to deal with methodological differences in burden conceptualization, operationalization, and measurement, and provide insights into the effectiveness and efficiency of burden-reduction actions.
\end{abstract}

Key words: Administrative burden; data collection; establishment surveys.

\section{Introduction}

The Fifth Principle of the United Nations' Fundamental Principles of Official Statistics (United Nations 1994, 2014) explicitly requires the data source to be selected "with regard to quality, timeliness, costs and the burden on respondents." Response burden in official business surveys is thus not a new issue. It has long been a concern for National Statistical Institutes (NSIs) (e.g., Sunter 1977; Astin 1994; Willeboordse 1997; Hedlin et al. 2005) for three types of reasons: political, methodological and strategic. The political reasons stem

1 University of Ljubljana, Faculty of Economics, Kardeljeva pl. 17, SI-1000 Ljubljana, Slovenia. Email: mojca.bavdaz@ef.uni-lj.si

2 Statistics Netherlands, Postbus 4481, 6401 CZ Heerlen, The Netherlands. Email: d.giesen@cbs.nl

3 University of Ljubljana, Faculty of Economics, Kardeljeva pl. 17, SI-1000 Ljubljana, Slovenia. Email: simona.cerne@ef.uni-lj.si

4 Statistics Norway, Pb 8131 Dep, NO-0033 Oslo. Email: tora.lofgren@ssb.no

5 Sogeti, Route de Longwy 36, L-8080 Bertrange, Luxembourg. Email: virginie.raymond-blaess@ sogeti.lu Acknowledgments: The research reported herein received funding from the European Community's Seventh Framework Programme (FP7/2007-2013) under grant agreement no. 244767. We acknowledge the valuable contributions of many colleagues, especially our BLUE-ETS partners Dag Gravem and Gustav Haraldsen (Statistics Norway); Rudi Seljak and Petra Mohorič Peternelj (Statistical Office of the Republic of Slovenia); Dan Hedlin, Boris Lorenc, and Andreas Persson (Statistics Sweden). We would also like to thank all respondents to our survey, the editors, and referees. The views expressed in this article are those of the authors and do not necessarily reflect policies of their employers or the European Commission. 
from the fact that administrative burdens imposed on businesses by legislation, which include mandatory statistical reporting, decrease the competitiveness of businesses by unproductively engaging their resources. Many countries have therefore implemented programs focused on reducing administrative burdens (OECD 2009). Examples of such programs include the Paper Work Reduction Act of 1980 in the United States and the President's Executive Order 13610 of May 10, 2012 to all US government agencies; Canada's Red Tape Reduction Commission (Red Tape Reduction Commission 2012); the EU 2007-2012 Action Programme for Reducing Administrative Burdens (European Commission 2007); and the EU Regulatory Fitness Programme (European Commission 2012b). The methodological reasons for concern about response burden are based on the growing evidence that excessive burdens may lead to problematic survey response behavior with potential consequences for data quality, especially nonresponse, late response, or measurement errors (see, for instance, Hedlin et al. 2005; Bavdaž 2010; Giesen 2012; Jones 2012; Lorenc et al. 2013; and Berglund et al. 2013). Perception of a survey task may even be more relevant in this context than the objective burden (e.g., Willeboordse 1997; Hak et al. 2003; Jones et al. 2005). Closely related to these methodological reasons are the strategic reasons, because good relations between NSIs and the business community have spillover effects in the whole field of official statistics. Businesses are an important stakeholder for NSIs because of their double role as reporting units and users of official statistics (Lorenc et al. 2012).

\subsection{Burden Concept and Measurement}

Despite its long presence and broad relevance, response burden is a vague concept. A politician may have in mind the total costs imposed on the whole business community, a manager may think of the time people take away from business tasks, a methodologist may focus on the feeling that a respondent experiences when confronted with a mandatory survey, and so on. Willeboordse (1997) defines response burden along four bipolar dimensions. First, he distinguishes between objective (actual) and subjective (perceived) response burden with regard to the choice of measurement perspective. Actual response burden means the money and/or time it takes to comply with data requests, and perceived burden refers to the respondents' assessment of how burdensome they find it to comply with the data request. Second, the concept may only refer to the burden itself (i.e., gross burden) or be broadened to consider the advantages of responding that reduce the amount of burden (i.e., net burden) for the unit. Third, the concept of response burden may concern the mere completion of the questionnaire (i.e., minimalistic burden) or include accompanying activities such as studying the instructions, data retrieval, and follow-up calls (i.e., maximalistic burden). Fourth, the concept may relate to the burden initially placed upon and, in an ideal world, expected from businesses (i.e., imposed burden) or to the burden that businesses bear de facto considering their actual response behavior (i.e., accepted burden). In an ideal world, all units would respond in a timely and accurate way; in reality, some units discard survey requests, others provide inaccurate data, and so on.

Moreover, different units of observation and various levels of aggregation may be relevant for different purposes. To illustrate the methodological challenges of burden measurement, Figure 1 shows relations between business units (BU; arranged in size 

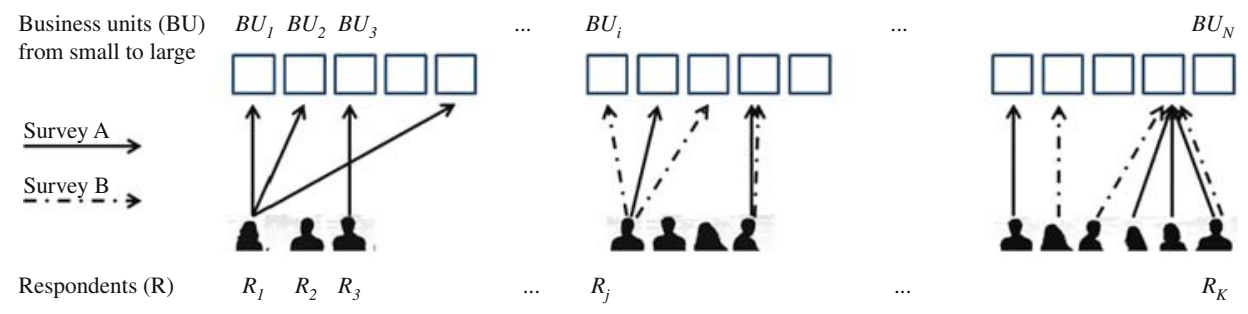

Fig. 1. Relations between business units $(B U)$ and respondents $(R)$ in two surveys

classes from small to large) and respondents (R) in two surveys (Survey A and Survey B). Small and also some medium-sized businesses typically hire accounting firms for all reporting (including statistical) matters. A single respondent may thus complete several questionnaires of the same survey for several businesses (see the left-most respondent involved in Survey A on behalf of several business units). By contrast, the same survey may involve several respondents at a large business (see the right-most group of respondents involved in Survey A for a large business unit). Two kinds of nesting are thus present that challenge the selection of the unit of observation: nesting business units within respondents and nesting respondents within business units. The scenario becomes loaded when surveys are added because the same respondent may be involved in more than one survey for either several businesses or a single business (see the middle group of respondents involved in both Survey A and Survey B).

The reality is more complex because surveys differ in their burden-relevant aspects (e.g., periodicity, questionnaire length, and data availability) and may involve other people in the response process in addition to respondents (e.g., data providers and authorities; see Bavdaž 2010). The same person can also have different roles in different surveys. Further complications relate to determining the relevant timeframe, delineation and dynamics of business units, changes in personnel involved in the response process, selection of the appropriate respondent for reporting burden data, and the timing and mode of collecting burden data.

The purpose of response burden monitoring ultimately determines what burden indicator (e.g., total or spread; actual or perceived) is relevant and at what level. The total actual burden at the national level may serve as a basic indicator of the total amount, progress, and outcome of national programs for administrative burden reduction. The total actual burden per survey may be considered when evaluating costs versus benefits of (new) statistical data. The spread of the total actual burden across business units, the total actual burden imposed on a business unit in a period of time, and the spread of a unit's burden in time may be useful when minimizing the impact that official surveys have at the business level. The burden that a respondent perceives in a specific survey task may contribute to better questionnaire design. Although perceptions are an inherent part of an individual, an indicator of perceived burden at a more aggregated level (a business unit, a survey, the national level) may provide greater insight because official surveys also "give rise to irritation and the perceived burden of statistics is often higher than the real burden" (European Commission 2012a, 33). 


\subsection{Research Problem and Research Questions}

Although the Ninth Principle of the European Statistics Code of Practice specifies that "the statistical authority monitors the response burden and sets targets for its reduction over time" (European Commission 2011), the guidelines for burden conceptualization, measurement, and reduction are rather general (cf. Eurostat 2009; European Statistical System 2012) and do not offer solutions to methodological challenges. Therefore NSIs are relatively flexible and independent, but are also quite solitary in selecting conceptual definitions of response burden, tackling measurement issues, and prioritizing burdenreduction actions. With so many possible conceptual and operational differences, any comparison (e.g., across NSIs) becomes at least questionable, if not invalid, which obstructs insights into the matter and its improvement.

Our study thus aimed to provide a systematic review of the state of affairs at NSIs to help NSIs to better understand their position in comparison with other NSIs, learn from other NSIs and set priorities for actions. The study attempted to answer the following research questions:

1. How do NSIs measure response burden caused by business surveys?

2. What actions do NSIs use to reduce the response burden caused by business surveys?

3. What is known about the effectiveness of these burden-reduction actions?

4. Which, if any, are the differences between NSIs in their approaches to response burden?

Section 2 of this article describes the research method, Section 3 presents results according to the research questions, and Section 4 concludes with a discussion and summary of the findings. For the bibliography of all available documentation on response burden from our literature search including references of unpublished documents, see supplementary material on the JOS website (Supplemental_material_Bibliography_Bavdaz_et_al).

\section{Research Method}

A stepwise approach was used to answer the research questions. First, an extensive literature search was carried out for the period 2006-2010 (for more details, see Giesen and Raymond-Blaess 2011). This review did not find much (comparable) information about response-burden issues across NSIs and it was expected that many relevant reports would not be publicly available or updated to reflect the latest situation. A survey was thus conducted in the second step.

\subsection{Questionnaire}

Based on the literature review, a questionnaire was developed (see Appendix 2) that aimed to provide an overview of response-burden measurement (Part A) and reduction (Part B), and to identify any reports (additional to the ones found in our literature search) documenting response-burden measurement, response-burden reduction actions, and the effects of response-burden reduction actions.

The draft questionnaire was first reviewed by project and external experts, then revised, pretested at the NSIs of the Netherlands, Norway, Slovenia, and Sweden, and once again 
revised. The pretests showed two main challenges. First, respondents did not have an overview of all types of burden-reduction actions within their NSIs. For example, knowledge of questionnaire design and knowledge of sampling and estimation strategies were typically in separate departments. Therefore, attempts were made to establish presurvey contact with all NSIs to inform them about the survey and find the best respondent or response coordinator. Second, specifying the scope of a burden reduction action created conceptual problems (e.g., whether to refer to the number of surveys or businesses or respondents) and practical ones (e.g., how to treat surveys of different periodicities and lengths). Priority was given to overview rather than detail, and so the decision was made to focus on surveys and to ask for the proportion of surveys to which an action was applied using an ordinal scale:

- None: in none of our business surveys,

- Some: in some, but less than $50 \%$,

- Most: in $50 \%$ or more, but not all,

- All: in all of our business surveys.

When developing questions about the response-burden measurement methods, four dimensions of response burden as defined by Willeboordse (1997) were taken into account:

- Objective (or actual) vs. subjective (or perceived) (Questions A1-A5 and A6-A8),

- Gross vs. net (Question A13),

- Imposed vs. accepted (Questions A5.3 and A5.2),

- Maximalistic vs. minimalistic (Question A4.a).

We asked whether the actual burden is calculated traditionally as time spent (Dale and Haraldsen 2007), in monetary costs as in the Standard Cost Model (European Commission 2009), or both. The perceived legitimacy of the survey request is probably an important aspect of how businesses perceive response burden (Dale and Haraldsen 2007), and so we also asked if NSIs had conducted any studies on how businesses perceive their organization. Furthermore, we asked about any registration of the NSI's response burden imposed on individual businesses and about any national registers of response burden caused by the government.

To assess which actions NSIs use for reducing response burden in business surveys, a list of possible reduction actions based on the literature review was created, but it only included those actions expected to be used by several NSIs and easy to capture with a single question; an open question was used to capture other actions (Question B5). Among two sets of questions, the first set referred to the last five years (2006-2010) and asked in what proportion of the NSIs' business surveys (none, some, most, or all surveys) the following actions had been implemented: reduction in sample sizes, reduction in the datacollection frequency, reduction in the number of requested items, and reduction in the number of recontacts with businesses (Question B1). The second set of questions referred to the current situation and asked for a list of thirteen statements to assess to which part of the NSIs business surveys (none, some, most, or all surveys) each statement applied. These statements were grouped by the use of alternatives to traditional data collection (Question B2), methods that make completing the questionnaire easier (Question B3), and actions 
that can improve communication and respondents' relationships to business surveys by attending to their needs (Question B4).

\subsection{Survey Implementation}

A letter with an invitation to participate in the web survey was sent to 45 NSIs in 43 countries covering all NSIs of the European Statistical System, (potential) candidate countries, and prominent NSIs in four non-European countries (see the list in Appendix 1). We included a request for relevant literature as an attachment to the invitation letter. We listed the literature we had already found related to that specific NSI (if any) and asked respondents to send us (references to) any other reports they could share with us. We specifically indicated that we were interested in any reports that describe the effects of burden-reduction actions on, for example, burden and data quality. This call for reports was also included as a question in the survey.

The web survey was online from November 2010 until February 2011. We saw that 41 of 45 NSIs from 39 of 43 countries responded. The achieved sample thus included 30 of the 31 NSIs in EU and EFTA countries, five of eight NSIs from (potential) candidate countries, and all six NSIs from non-European countries. Most of them responded electronically (a paper version was produced for others when requested) and after being sent reminders. For a few NSIs, we had to follow up contacts by telephone or email in order to clarify their answers or attempt to get substantive answers instead of "don't know." Our discussions with respondents revealed that it was sometimes challenging for them to answer our survey questions for all business surveys at their institute, especially because burden-measurement practices can vary over surveys and information about them does not seem to be located in a single place.

\subsection{Analysis}

The analysis consisted of various types of descriptive analysis. A cluster analysis aimed at identifying groups of NSIs with similar approaches to burden measurement and reduction. It was based on six binary variables describing the presence (or absence) of a specific practice:

- Actual response burden is measured in the five-year period studied (2006-2010),

- Perceived response burden is measured in the five-year period studied (2006-2010),

- Actual response burden is measured annually in the five-year period studied (2006-2010),

- Database on response burden for each business unit is kept by the NSI,

- Samples are coordinated and/or rotated (survey holidays) for all or most surveys,

- Electronic versions of self-completion questionnaires are available for all or most surveys.

The presence of a practice is considered positive: measurement of actual and perceived burden suggests NSIs' awareness of the problem; annual measurement of actual burden and a database at the business level indicate the possibility of monitoring and managing the burden; sample coordination and/or rotation for all or most surveys points to the use of more 
advanced statistical methods for burden reduction in a systematic way; and electronic questionnaires for all or most surveys suggest the adoption of modern technology.

After performing tests of several clustering methods, the clusters were identified using Ward's hierarchical clustering method (Ward 1963) based on the squared Euclidean distance for binary data. Analyses were done in R (R Core Team 2014) with the package cluster (Maechler et al. 2014). Comparisons of the clustering results were based on functions from the R-packages $f p c$ (Hennig 2014) and e1071 (Meyer et al. 2014).

The survey answers were treated as confidential unless the information was already in the public domain.

\section{Results}

\subsection{Measurement of Response Burden}

The majority of NSIs surveyed measure actual burden (i.e., the money and/or time it takes to comply); 34 out of 41 NSIs answered "yes" to the question: "In the last five years, 2006-2010, has the actual response burden incurred by businesses to comply with survey requests of your organization been calculated?" Nearly half of them (20) did this annually. Several NSIs that measure actual burden explained that this was only done for certain surveys; for example, some EU surveys or all mandatory surveys. Our follow-up contacts revealed that at least one respondent had interpreted our question as whether total response burden was calculated (for all survey requests). This lack of clarity in the question phrasing may have caused some other NSIs to answer "no" even though in fact they did carry out some kind of burden measurement. The reality might thus be slightly better than the results suggest.

NSIs measure perceived burden (i.e., respondents' assessments of how burdensome they find it to comply with the survey requests) less frequently: only twelve out of 41 NSIs measured perceived burden in the five-year period studied, most of those had also measured actual burden. Two-thirds of those measuring perceived burden did it every year. 17 NSIs reported that they had conducted studies on businesses' perception of the usefulness of statistics.

\subsubsection{Measurement of Actual Response Burden}

Out of 34 NSIs 16 calculated actual burden in time costs only and the same number of NSIs calculated both time and monetary costs, often by multiplying the time spent responding to surveys by an average wage rate. Some other NSIs also mentioned similar approaches, such as a monitoring system for the mean number of questionnaires filled in per business in a given time period.

NSIs reported using several types of data sources to calculate actual response burden. The most popular were data provided by survey respondents (29 NSIs) and expert estimates (25 NSIs). 13 NSIs used qualitative studies to assess the costs of complying. Other data sources were also reported: the frequency with which a business was drawn in samples (a practice also mentioned by other countries in some surveys); adjusted data from a previous survey; and interview time. 
Table 1. Potential sources of burden explicitly included in the calculation of actual response burden $(N=33$; one institute with an actual burden measurement is missing)

\begin{tabular}{lccc}
\hline Sources of actual response burden & Yes & No & Don't know \\
\hline $\begin{array}{l}\text { Filling in the questionnaire. } \\
\text { Retrieving, collecting, and compiling the information }\end{array}$ & 31 & 1 & 1 \\
$\quad$ requested. & 28 & 4 & 1 \\
$\begin{array}{l}\text { Reading questions and instructions. } \\
\text { Administrative tasks (e.g., coordination) involved in }\end{array} \quad 18$ & 10 & 2 \\
$\quad \begin{array}{l}\text { survey completion. } \\
\text { Record formation specifically done for reporting }\end{array} \quad 16$ & 12 & 5 \\
$\quad \begin{array}{l}\text { obligations. } \\
\text { Recontacts with businesses about the data } \\
\quad \text { provided. }\end{array}$ & 13 & 16 & 4 \\
Other sources of response burden. & 3 & 18 & 12 \\
\hline
\end{tabular}

Of the 29 NSIs that used burden data provided by survey respondents, 14 collected it from subsamples and 21 collected it at the same time as the survey data they related to. Often, NSIs used several types of data sources to calculate response burden (the maximum reported by a single NSI was four different types of data sources).

Table 1 shows which potential sources of burden were explicitly included in the calculation of actual burden. For example, 18 NSIs included administrative tasks, 16 NSIs included record formation, and 13 NSIs included recontacts as part of the burden. These results suggest that response burden was operationally defined and measured in very different ways. Large discrepancies were further confirmed when comparing individual combinations of these sources. Only eight NSIs took into account all six sources of burden given in Table 1 and seven NSIs included all these sources except recontacts with businesses. Other NSIs reported using several different combinations of these sources. The most consistently used were the top three sources in Table 1 (filling in the questionnaire; retrieving, collecting and compiling requested information; and reading questions and instructions), which 25 NSIs reported they included in the calculation of actual burden. The other aspects of burden mentioned were "out-of-pocket costs/external costs" and "sixteen standard activities based on the standard cost model" (SCM Network 2005, 26-27).

An important difference in burden measurement is whether all questionnaires dispatched or only those returned are taken into account. 13 out of 34 NSIs measuring burden considered only the number of dispatched questionnaires and eleven NSIs only the number of returned questionnaires, whereas six NSIs considered both. A combination of both figures was used in some NSIs that indicated the use of different methods for different surveys. Ireland, on the other hand, does in fact publish two response-burden figures, one according to the Standard Cost Model (with the assumption of full compliance) and another one for the responding units only (Central Statistics Office 2012). The burden can also be estimated for nonrespondents (e.g., time taken to reach the decision not to respond).

\subsubsection{Registers of Response Burden}

Sixteen out of forty-one NSIs reported that they had a database (a register) of the burden imposed on each business unit. New Zealand used it to monitor burden ("respondent 
load") at the business level (Merrington et al. 2009). For each business they calculated the response burden and compared it to the relevant load thresholds for a business of that size. If businesses were unfairly burdened they were given some relief (e.g., participation in fewer surveys).

Moreover, in some countries registers were kept at the national level in order to monitor and/or reduce burden caused by all government surveys. These registers may be seen as a complement to NSIs' actual burden measurements. Such registers were reported by nine NSIs, such as the Statistical Clearing House (www.sch.abs.gov.au) in Australia, the Office of Management and Budget (Office of Information and Regulatory Affairs 2006) in the United States, and the Brønnøysund Register Centre (www.brreg.no) in Norway.

\subsection{Burden-reduction Actions}

Seventeen burden-reduction actions were assessed in the survey to ascertain the proportion of business surveys in which these actions had been applied. The arithmetic mean number of actions applied by the surveyed NSIs to at least some of their business surveys was twelve. One NSI had implemented none of the proposed actions and four NSIs had implemented 16 of the 17 proposed actions.

Figure 2 shows the extent to which the analyzed burden-reduction actions were present among the NSIs surveyed and how many of them applied these actions to at least half of their surveys. Burden-reduction actions that were more widely present across the NSIs tended to be more widely used within NSIs. Respondents could contact a help desk (Help desk) in nearly all NSIs and for a majority of surveys. Electronic versions of selfcompletion questionnaires (E-qnr), help for respondents on a website (Website help), and information on the concrete use of the statistical output based on the survey request (Concrete use) were also widely used, but around a third of NSIs surveyed still applied them to less than half of their surveys. Questionnaires were also widely tested with respondents (Qnr testing), but only around half of the NSIs surveyed used this testing in the majority of their surveys.

Some burden-reduction actions were present in at least 30 out of 41 NSIs surveyed, but they were not applied as often to the majority of surveys at these NSIs: sample coordination and/or rotation (Sample coord) was applied in the majority of surveys by only 13 NSIs, and register data replaced (part of) the data collection in the majority of surveys by nine NSIs (Register data). Despite their presence in more than 30 NSIs, only six NSIs applied the following three burden reduction actions to the majority of surveys: using smaller sample sizes (Smaller samples), requesting fewer survey items (Fewer items), and allowing nonautomatic fixed format files such as Excel (Excel).

Burden-reduction actions that were hardly ever or never used in the majority of surveys even when they were present in an NSI included: preprinting data from previous reporting periods in the questionnaire (Preprinting), fewer recontacts with businesses (Fewer recontacts), reduction of the data collection frequency (Less frequently) and the possibility of using automatic extraction from the businesses' administrative systems (XBRL). By contrast, of 19 NSIs that used a survey calendar to inform businesses of forthcoming survey requests (Survey calendar), as many as 14 used the calendar for the majority of surveys. Around half of the NSIs surveyed also used account managers for contacts with 


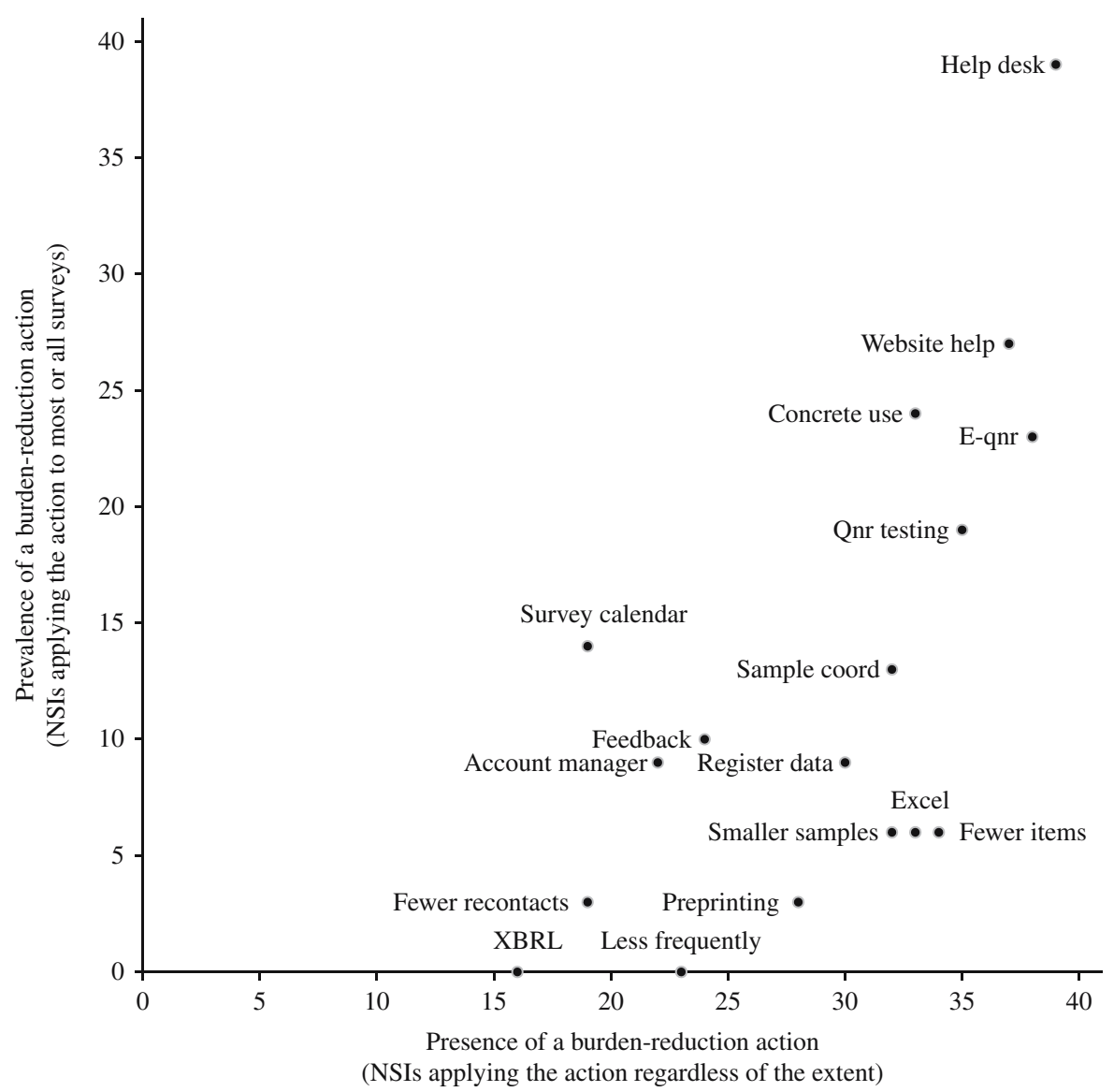

Fig. 2. Presence and prevalence of burden-reduction actions in NSIs surveyed $(N=41)$. Note: For complete descriptions of labels see Appendix 2, Questions B1-B4.

large businesses (Account manager) and personalized feedback for respondents (Feedback), but only about ten NSIs used those actions in the majority of surveys.

The open question containing a request to report any other unspecified reduction action yielded many responses. Some of them could be assigned to the themes of responses to the closed-ended questions. For example, some respondents interpreted the use of register data as something different to the use of administrative data. Appendix 3 gives an overview of the remaining other reduction actions and the number of times they were mentioned. It must be kept in mind that these actions are probably used at more NSIs, but these were not followed up in this study.

\subsection{Effectiveness of Burden-reduction Actions}

In response to our request for reports on the effects of burden-reduction actions, twelve NSIs sent us one or more reports about their efforts to reduce response burden. Some of these reports describe the development of response burden over time and, sometimes, separately for specific surveys. Examples of such publicly available reports are 
Fröhlich et al. (2012) and Central Statistics Office (2012). However, very few publicly available studies investigate the effects of specific actions on response burden (Giesen and Raymond-Blaess 2011). Some exceptions are Ojo and Ponikowski (2010), who carried out a simulation study to explore the effects of dependent sampling, a method aiming at reducing response burden on the precision of estimates; a technical report by the Hungarian Statistical Office (2004) that describes a study on the expected effects of proposed burden-reduction measures on respondents and data users; and a study by Statistics Belgium (2010) that specifically states the effects of burden-reduction actions both in terms of response burden and in staff costs before and after implementation.

\subsection{Approaches to Response Burden}

Hierarchical clustering revealed three clusters (see Appendix 4 for details of cluster identification). The smallest cluster had approximately a quarter of the NSIs and the two other clusters had each about half of the remaining NSIs (see Table 2). The differences among clusters are particularly large with regard to the measurement of perceived response burden (in Cluster 2 all NSIs have already done it compared to only $29 \%$ of all NSIs) and much more moderate when it comes to the measurement of actual response burden (the proportion of NSIs in Cluster 1 that have already done it is $63 \%$, compared to $83 \%$ overall).

NSIs in Cluster $1(N=16)$ manifested the most modest activities related to response burden issues. This cluster contains all NSIs that carried out none, one, or two of the six activities studied. About two-thirds of NSIs in this cluster measured the actual response burden in some way in the five-year period studied and less than half of them did it annually. The other four activities were present in a maximum of two NSIs. The defining

Table 2. Cluster sizes and proportions of NSIs within clusters with a specific practice considered in clustering

\begin{tabular}{lcccc}
\hline & $\begin{array}{c}\text { Cluster 1 } \\
(N=16) \\
\text { Modest } \\
\text { response } \\
\text { burden } \\
\text { activity } \%\end{array}$ & $\begin{array}{c}\text { Cluster } 2 \\
(N=10) \\
\text { Awareness of } \\
\text { perceived } \\
\text { response } \\
\text { burden } \%\end{array}$ & $\begin{array}{c}\text { Cluster } 3 \\
(N=15) \\
\text { Actual } \\
\text { response } \\
\text { burden in } \\
\text { focus } \%\end{array}$ & $\begin{array}{c}\text { Total } \\
(N=41) \%\end{array}$ \\
\hline $\begin{array}{c}\text { Actual response } \\
\text { burden measured }\end{array}$ & 63 & 90 & 100 & 83 \\
$\begin{array}{c}\text { Perceived response } \\
\text { burden measured }\end{array}$ & 13 & 100 & 0 & 29 \\
$\begin{array}{c}\text { Actual response burden } \\
\text { measured annually }\end{array}$ & 25 & 50 & 73 & 39 \\
$\begin{array}{c}\text { NSI database on } \\
\text { response burden }\end{array}$ & 13 & 20 & 80 & 32 \\
$\begin{array}{c}\text { Sample coordination } \\
\text { and/or rotation for all } \\
\text { or most surveys }\end{array}$ & 0 & 60 & 47 & 56 \\
$\begin{array}{c}\text { Electronic questionnaires } \\
\text { for all or most surveys }\end{array}$ & 6 & 80 & 93 & \\
\hline
\end{tabular}


characteristic of this cluster is that none of its NSIs applied sample coordination and/or rotation to the majority of their surveys.

NSIs in both Cluster $2(N=10)$ and Cluster $3(N=15)$ showed much more activity with regard to response burden compared to Cluster 1 because they reported between three and five of the six activities. However, they had a different focus. NSIs in Cluster 3 concentrated on actual response burden. They all measured it in some way in the five-year period studied and the majority measured it annually, but none of them measured perceived response burden. By contrast, measurement of perceived response burden may be considered as the defining characteristic of Cluster 2, because all of its NSIs measured the perceived burden in some way in the observed five-year period. The other larger difference between Cluster 2 and Cluster 3 relates to response-burden databases. The majority of NSIs in Cluster 3 kept such a database, whereas only a minority of NSIs in Cluster 2 did. A closer look at the NSIs in Cluster 2 reveals that half of these NSIs applied sample coordination and/or rotation to the majority of their surveys and at the same time reported having no response-burden database. It is possible to claim that even these NSIs were practically ready for burden management, because burden registration is just a step away if a system infrastructure for sample coordination is already in place.

\section{Discussion}

Our study aimed to provide an overview of the situation regarding response-burden issues, focusing on Europe but with some extra-European countries included. It became clear during data collection that these issues cannot be covered in great detail because the data on burden-measurement and -reduction actions were either scattered around the NSIs or nonexistent. Most NSIs did not have a central person or department coordinating burdenmeasurement and burden-reduction actions. Notable exceptions were the Ombudsman for response burden at Statistics Canada (Sear 2011) and the Respondent Advocate at Statistics New Zealand (Statistics New Zealand 2008). Therefore it cannot be excluded that some actions were underreported and that the reality might be slightly better than the results suggest.

A closer inspection of burden measurement revealed that there were large differences in methodologies between NSIs and also within NSIs. These differences referred to the conceptual and operational definitions (e.g., monetary burden versus time burden, inclusion of recontacts and nonrespondents), type and number of data sources used, calculation procedures, and so on. Some differences might be negligible for the burden level (e.g., inclusion of nonrespondents when the response rate is high) but others quite substantial (e.g., recontacts in a complex survey with many questionable items). These methodological differences reflect differences in both the purpose and quality of burden measurement. In order to address the political reasons for burden measurement it might be sufficient for an NSI to consistently use current measurement through time, thus tracking only changes in the level of actual burden, which is quite low when presented in relative terms (e.g., compared to other administrative burdens). Comparisons for methodological or strategic reasons based on methodologically different indicators within an NSI and across NSIs are, however, much more problematic because they focus on burden levels 
(e.g., acceptable levels of actual burden per business, levels of perceived burden that affect a respondent's behavior in a survey, effects of a certain burden reduction action, etc.).

Our study results also indicate that most NSIs surveyed actively engage in activities related to response burden. The great majority of NSIs surveyed had - in accordance with the European Statistics Code of Practice - measured actual response burden in the fiveyear period studied, nearly half of them annually. These NSIs seemed prepared to respond to political pressures because they had a means of monitoring the actual burden imposed on businesses at the national level that is typically at the heart of political debates. Some NSIs also had policies guiding their burden-reduction activities. However, actions that directly reduce actual burdens imposed on businesses were not so widely applied within NSIs, regardless of whether they were common across NSIs (e.g., fewer survey items requested and smaller sample sizes) or less common (e.g., fewer recontacts with businesses and reduction of data-collection frequency). The highest prevalence was noted for register data replacing (part of) data collection, which nonetheless was still not common.

When analyzing burden-reduction actions, the first impression was that the NSIs really focused on strategic reasons and tried to establish and/or improve their relations with the business community by offering help and explaining how the collected data would be used. These actions were probably relatively easy to implement because they did not require much change in the work organization. Other actions likely required greater interventions because they demanded redesigned processes (e.g., electronic versions of self-completion questionnaires), a redesigned information system (e.g., sample coordination and/or rotation, survey calendar) or a broader knowledge (e.g., account managers for contacts with large businesses). Among these actions, the NSIs surveyed performed best on the electronic versions of self-completion questionnaires, probably because of other government initiatives for electronic reporting (e.g., on taxes), expected cost savings and business pressures. If the NSIs wanted to manage actual burden well that is, to monitor its amount and spread over time - they first needed burden data per business over time. Such databases or registers were, however, set up in less than half of the NSIs surveyed, although a few NSIs might be close to having registers of this kind because they possessed the infrastructure for survey coordination.

Some actions mentioned above could also be understood as methodologically motivated burden-reduction actions, especially when considering the perceived burden, such as offering electronic versions of questionnaires, offering help, and explaining the reasons for survey requests (addressing the "irritation" burden, see High Level Group of Independent Stakeholders on Administrative Burdens 2009). Less than a third of the NSIs surveyed, however, measured the perceived response burden. Given that the survey questionnaire is the essential instrument of data collection and the main "source" of any kind of burden, and that the European Statistics Code of Practice explicitly prescribes systematic testing of questionnaires prior to the data collection, it was expected that testing questionnaires with respondents would be common across NSIs. A surprising finding was that half of the NSIs surveyed used testing with respondents in less than half of their surveys. However, some NSIs also had other initiatives that promised to make a questionnaire's completion easier, such as designing survey questions to be as close as possible to accounting categories, regularly reviewing questionnaires, testing web-questionnaire usability, and so on. 
Given the burden-reduction actions implemented, the NSIs surveyed seemed to work simultaneously on political, strategic, and methodological reasons. Our study does not reveal how or why the NSIs decided on their combinations of implemented actions. Variations among the NSIs in these combinations may partly be caused by structural differences such as legal limitations (particularly with respect to getting access to administrative data) or other government initiatives, and by the human, technological, and financial resources available. They probably also reflect the fact that little is known about the effects of various response-burden reduction actions on response burden, data quality, and (net) costs for NSIs. Some burden-reduction actions have an obvious effect on actual response burden (such as substituting direct data collection with administrative sources), but even for these the effects on both actual burden and (net) costs are not often measured or publicized. Furthermore, there is little evidence for other actions, and there is even less evidence about effects on perceived response burden, data quality, and (net) costs for NSIs.

This lack of data is quite surprising for an information producer in the era of big data and omnipresent demands for improved efficiency. This overview of the situation might stir the NSIs to start collecting evidence in order to understand their own positions better. The overview discusses actions used at the time of data collection and indicates to what extent most of these actions were present and used in the NSIs surveyed, thus establishing a common reference or "norm". Every NSI can now better compare itself to other NSIs. Such benchmarking then urges the NSIs to respond by at least reconsidering, if not improving, their own activities (see Triantafillou 2007). The best-performing NSIs may be encouraged to fill the remaining gaps and the underperforming NSIs to reach the "average". Benchmarking can be supported by the cluster-analysis results, which suggested marked disparities in approaches to response burden among the NSIs surveyed. Some differences between the NSIs might be attributable partly to the diverse institutional environments in which they operate. These diverse institutional environments represent different levels of red tape, social responsibility, business friendliness, information disclosure, access to modern technology, and so on, but also different historical backgrounds. The situation seemed especially challenging for the NSIs of some smaller countries. These NSIs in particular may benefit from sharing knowledge on response burden among the NSIs in order to avoid reinventing the wheel.

\subsection{Future Work and Research}

It seems that successful management of response burden requires different disciplines within an NSI to work together; at least experts from statistical units, methodology, data collection, and communication should be involved. A central location for measuring and managing response burden seems an efficient way to facilitate and stimulate such cooperation within and across NSIs. It should also result in more data for benchmarking purposes, but these data can only be useful if they are comparable.

Methodological differences in burden conceptualization, operationalization, and measurement might be dealt with, to a certain extent, by estimating the effects of these differences on the results. Current knowledge on these issues is, however, limited. We therefore call for more research in order to better understand what concepts are relevant for 
what purpose, what sources of burden are (empirically) important in what context, what data sources are reliable, how often to measure the burden, how to measure the perceived burden of a single respondent and multiple respondents, and so on.

A longer-term objective, although one not easy to achieve, should be to attain some harmonization of burden definitions, measurement, and indicators with the purpose of allowing direct comparisons without corrections. Moreover, new indicators might be developed to quantify the burden per data point collected. The 2007 Handbook for Monitoring and Evaluating Business Survey Response Burden could be used as a starting point. A standardized framework, however, requires active dissemination and follow-up; the active involvement of Eurostat and other international organizations would certainly be helpful for such processes (see also Giesen et al. 2011).

We also recommend that NSIs first of all document and monitor their burden-reduction initiatives better, and share their knowledge both within and between NSIs. We also recommend more studies comparing burden-reduction action alternatives or at least describing the "before and after" situation to be able to make better decisions about priority actions. In order to make well-informed decisions, a step forward in the research into business survey data-collection methodology is indispensable. This research should take into account that it may not be easy to change the opinions and behavior of respondents to business surveys, who already have established routines and attitudes concerning NSI survey requests. The research into effects of burden-reduction actions should include both novice and experienced respondents and should monitor long-term effects. Furthermore, it seems advisable to design studies that can detect how business characteristics such as size class, type of industry, and past response behavior affect their reactions to burden-reduction actions. It may well be that NSI actions can be more effective and efficient if tailored to these characteristics. 
Appendix 1: List of Targeted NSIs $(N=45)$ With An Indication of Nonresponse NSIs of the EU and EFTA Countries $(27+4=31$ Units; 1 Nonrespondent $)$

1. Austria: Statistik Austria

2. Belgium: Statistics Belgium

3. Bulgaria: National Statistical Institute

4. Cyprus: Statistical Service of Cyprus

5. Czech Republic: Czech Statistical Office

6. Denmark: Statistics Denmark

7. Estonia: Statistics Estonia

8. Finland: Statistics Finland

9. France: National Institute of Statistics and Economic Studies (INSEE)

10. Germany: Federal Statistical Office

11. Greece: National Statistical Service of Greece

12. Hungary: Hungarian Central Statistical Office

13. Iceland: Statistics Iceland

14. Ireland: Central Statistics Office Ireland

15. Italy: Italian National Institute of Statistics (ISTAT)

16. Latvia: Central Statistical Bureau of Latvia

17. Liechtenstein: Office of Statistics

18. Lithuania: Statistics Lithuania

19. Luxemburg: National Institute of statistics and economic studies (STATEC)

20. Malta: National Statistics Office

21. Netherlands: Statistics Netherlands

22. Norway: Statistics Norway

23. Poland: Central Statistical Office

24. Portugal: Statistics Portugal

25. Romania: National Institute of Statistics

26. Slovakia: Statistical Office of the Slovak Republic

27. Slovenia: Statistical Office of the Republic of Slovenia

28. Spain: National Statistics Institute

29. Sweden: Statistics Sweden

30. Switzerland: Swiss Federal Statistical Office

31. United Kingdom: Office for National Statistics

\section{NSIs of the (potential) Candidate Countries (8 Units; 3 Nonrespondents)}

1. Albania: Institute of Statistics

2. Bosnia and Herzegovina: Agency for Statistics of Bosnia and Herzegovina

3. Croatia: Central Bureau of Statistics

4. FYROM: Statistical Office of Macedonia

5. Kosovo: Statistical Office of Kosovo

6. Montenegro: Statistical Office of Montenegro (MONSTAT) 
7. Serbia: Statistical Office of the Republic of Serbia

8. Turkey: Turkish Statistical Institute

\section{Non-European NSIs (6 Units; no Nonrespondents)}

1. Australia: Australian Bureau of Statistics

2. Canada: Statistics Canada

3. New Zealand: Statistics New Zealand

4. USA: Bureau of Labor Statistics

5. USA: Census Bureau

6. USA: National Agricultural Statistics Service

\section{Appendix 2: Web Survey Questionnaire}

Note: Labels for burden-reduction actions given in bold in brackets in questions B1-B4 were added for easier interpretation of Figure 2 and did not appear in the questionnaire.

\section{Part A: Measurement of Response Burden}

A1. $\quad * *$ Al Help text: Businesses = organizations that produce goods and services for profit. Actual response burden = the money and/or time it takes to comply with survey requests. **

This question is about actual response burden. We define actual response burden as the money and/or time it takes to comply with survey requests.

In the last five years, 2006-2010, has the actual response burden incurred by businesses to comply with survey requests of your organization been calculated? ** 1 choice only, no empty **

1. Yes $\rightarrow \mathrm{A} 2$

2. No $\rightarrow$ A5

3. Don't know $\rightarrow$ A5

A2. Has the actual response burden been calculated in time spent, monetary costs or both?

** 1 choice only, no empty **

1. In time costs only

2. In monetary costs only

3. Both in time spent and monetary costs

4. Don't know

A3.a In the last five years (2006-2010), have the following kinds of data have been used to calculate the actual response burden of businesses?

** 1 choice only, no empty ** 


\begin{tabular}{|l|l|}
\hline Estimates from staff/experts. & Yes/No/Don't know \\
\hline $\begin{array}{l}\text { Qualitative studies assessing the costs of } \\
\text { complying (for example observation of respondents } \\
\text { completing the questionnaire). }\end{array}$ & Yes/No/Don't know \\
\hline $\begin{array}{l}\text { Information provided by respondents in surveys } \\
\text { (for example through an additional survey } \\
\text { question on time taken to complete } \\
\text { questionnaire). }\end{array}$ & Yes/No/Don't know \\
\hline Other data** if Other data = yes then A3.b** & Yes/ No/Don't know \\
\hline
\end{tabular}

A3.b Please briefly describe the other data used to calculate the actual response burden of businesses.

** Large memo field **

A4.a In the last five years (2006-2010), which potential sources of response burden have been explicitly included in the calculation of businesses' actual response burden? ** 1 choice only, no empty **

\begin{tabular}{|l|l|}
\hline $\begin{array}{l}\text { Record formation specifically done for } \\
\text { reporting obligations. }\end{array}$ & Yes/No/Don't know \\
\hline $\begin{array}{l}\text { Administrative tasks (e.g., coordination) } \\
\text { involved in survey completion. }\end{array}$ & Yes/No/Don't know \\
\hline Reading questions and instructions. & Yes/No/Don't know \\
\hline $\begin{array}{l}\text { Retrieving, collecting and compiling } \\
\text { requested information. }\end{array}$ & Yes/No/Don't know \\
\hline Filling in the questionnaire. & Yes/No/Don't know \\
\hline Recontacts with businesses about the data provided. & Yes/No/Don't know \\
\hline $\begin{array}{l}\text { Other sources of response burden** if Other } \\
\text { sources }=\text { yes then A4.b } * *\end{array}$ & Yes/No/Don't know \\
\hline
\end{tabular}

A4.b Please briefly describe the other sources of response burden used to calculate the actual response burden of businesses.

** Large memo field **

A5. For the last five years (2006-2010), which of the following statements are true for the methods used to calculate the actual business response burden due to survey requests of your organization?

** 1 choice only, no empty ** 


\begin{tabular}{|l|l|}
\hline Actual response burden is calculated each year. & Yes/No/Don't know \\
\hline $\begin{array}{l}\text { Actual response burden is based on the number } \\
\text { of businesses that respond to survey requests. }\end{array}$ & Yes/No/Don't know \\
\hline $\begin{array}{l}\text { Actual response burden is based on the total number } \\
\text { of survey requests sent out (including nonresponse). }\end{array}$ & Yes/No/Don't know \\
\hline $\begin{array}{l}\text { Data used for actual response burden calculation } \\
\text { are based on information provided by samples } \\
\text { of business-survey respondents. }\end{array}$ & Yes/No/Don't know \\
\hline $\begin{array}{l}\text { Data on actual response burden are collected } \\
\text { at the same time as the survey data they } \\
\text { relate to (integrated or attached to survey request). }\end{array}$ & Yes/No/Don't know \\
\hline
\end{tabular}

A6. ** A6 Help text: Perceived response burden $=$ the respondents assessment/qualification of how burdensome the survey request is. **

This question is about perceived response burden. We define perceived response burden as the respondents' assessments of how burdensome they find it to comply to the survey requests. This could be measured by questions on how time consuming and/or burdensome they think the survey questionnaire is.

In the last five years, 2006-2010, has the perceived response burden of business respondents caused by your survey requests been measured in some way?

1. Yes $\rightarrow$ A6

2. No $\rightarrow$ A9

A7. Has the perceived response burden of business respondents caused by your data requests been measured at least once a year in the last five years (2006-2010)?
1. Yes
2. No
3. Don't know

A8. Are the data on perceived response burden of businesses collected at the same time as the survey data they relate to?

1. Yes

2. No

3. Don't know

A9.a Do you have any additional information about the calculation and measurement of business response burden that would help us understand your practices? Further on in this questionnaire you can give references to any documents you might be able to share on response-burden measurement.

1. Yes

2. No $\rightarrow \mathrm{A} 10$ 
A9.b ** If A9.a $=$ yes then A9.b

Please put any additional information on the calculation and measurement of business response burden below.

Large memo field

A10. Does your organization keep a database on response burden for each business unit? By this we mean a register-like database that contains information on the total response burden for each business.
1. Yes
2. No
3. Don't know

A11. In your country, is there an authority or register that records survey requests posed on businesses by your organization as well as by other governmental organizations? ** 1 choice only, no empty **
1. Yes
2. No $\Rightarrow$ A 13
3. Don't know $\Rightarrow \mathrm{A} 13$

A12. What is the name of the authority or register that records data requests by government organizations?

** Medium sized memo field **

A13. In the last five years, 2006-2010, has any study been done on how businesses perceive your organization - either in their capacity of data providers, data users or both? Please include any studies on businesses' perceived usefulness of statistics. ** 1 choice only, no empty **
1. Yes
2. No $\rightarrow$ A15
3. Don't know

A14. Please describe how the data on businesses' appreciation of your organization have been collected. Any related documents about this you can share with us can be mentioned in question A16.

** large memo field **

A15. Can you help us find any recent (2005-2010) reports on how your institute measures business response burden and/or the businesses' appreciation for your institute. As an attachment to the invitation letter for this survey we included a list of papers we already found for your organization (if any).

Please enter any (other) references to reports below or send the reports to rbsurvey@cbs.nl or to Deirdre Giesen, Divison of Methodology and Quality, Room 1C33, PO Box 4481, $6401 \mathrm{CZ}$ Heerlen, The Netherlands. 
A16. Who has answered the questions above on the measurement of response burden?

Name:

$----N o e m p t y$

Function:

----Optional field

Specific domain of expertise:

----Optional field

Department:

---- Optional field

E-mail:

Telephone number:

---- Noempty, email check

$----N o e m p t y$

A17.a Who should we contact in your organization for additional information on the measurement of response burden?

** 1 choice only, no empty **

- Same person as mentioned in previous question yes/no

- Other person(s) yes/no

\section{A17.b If Other person(s) is yes than A17b}

Please mention name, telephone number, e-mail address and, if applicable, specific domain of expertise of the person(s) we can contact for additional information on the measurement of response burden in your organization.

Large memo field

\section{Part B Reduction of Response Burden}

The goal of the following questions is to assess which practices national statistical institutes use that can reduce response burden in business surveys.

B1 In the last five years (2006-2010), in which part of your business surveys have the following actions been implemented?

** 1 choice only, no empty **

- None: in none of our business surveys

- Some: in some, but less than 50\%

- Most: in $50 \%$ or more, but not all

- All: in all of our business surveys

\begin{tabular}{|l|l|}
\hline Reduction of sample size(s). (Smaller samples) & none/some/most/all/don't know \\
\hline $\begin{array}{l}\text { Reduction of the frequency of data collection. } \\
\text { (Less frequently) }\end{array}$ & none/some/most/all/ don't know \\
\hline $\begin{array}{l}\text { Reduction of the number of requested items in } \\
\text { survey requests. (Fewer items) }\end{array}$ & none/some/most/all/ don't know \\
\hline $\begin{array}{l}\text { Reduction of the number of recontacts with } \\
\text { businesses. (Fewer recontacts) }\end{array}$ & none/some/most/all/ don't know \\
\hline
\end{tabular}


B2 Currently, to which part of your business surveys does each statement below apply? ** 1 choice only, no empty **

- None: to none of our business surveys

- Some: to some, but less than $50 \%$

- Most: to $50 \%$ or more, but not all

- All: to all of our business surveys

\begin{tabular}{|l|l|}
\hline $\begin{array}{l}\text { Register information has replaced (part of) } \\
\text { the data collected from businesses. } \\
\text { (Register data) }\end{array}$ & none/some/most/all/don't know \\
\hline $\begin{array}{l}\text { (Part of) the data can be provided by } \\
\text { automatic extracted files from the } \\
\text { businesses' administrative systems, for } \\
\text { example XBRL. (XBRL) }\end{array}$ & none/some/most/all/don't know \\
\hline $\begin{array}{l}\text { (Part of) the data can be provided by } \\
\text { non-automatic fixed format files, for } \\
\text { example excel files. (Excel) }\end{array}$ & none/some/most/all/don't know \\
\hline $\begin{array}{l}\text { Samples are coordinated and/or rotated } \\
\text { (survey holidays). (Sample coord) }\end{array}$ & none/some/most/all/don't know \\
\hline
\end{tabular}

B3 Currently, to which part of your business-survey questionnaires does each statement below apply?

** 1 choice only, no empty **

- None: to none of our business-survey questionnaires

- Some: to some, but less than $50 \%$

- Most: to $50 \%$ or more, but not all

- All: to all of our business-survey questionnaires

\begin{tabular}{|l|l|}
\hline $\begin{array}{l}\text { Data of previous reporting periods are preprinted } \\
\text { in the questionnaires (e.g., dependent } \\
\text { interviewing). (Preprinting) }\end{array}$ & none/some/most/all/ don't know \\
\hline $\begin{array}{l}\text { Questionnaires have been tested with respondents } \\
\text { to assess how well they understand the } \\
\text { questionnaire and are able to provide } \\
\text { the data. (Qnr testing) }\end{array}$ & none/some/most/all/ don't know \\
\hline $\begin{array}{l}\text { Electronic versions of self-completion } \\
\text { questionnaires are available. (E-qnr) }\end{array}$ & none/some/most/all/ don't know \\
\hline
\end{tabular}

B4 Currently, to which part of your business surveys does each statement below apply? ** 1 choice only, no empty **

- None: to none of our business surveys

- Some: to some, but less than $50 \%$ 
- Most: to $50 \%$ or more, but not all

- All: to all of our business surveys

\begin{tabular}{|l|l|}
\hline $\begin{array}{l}\text { Survey requests are included in a survey calendar } \\
\text { that gives businesses an overview of which } \\
\text { surveys they can expect from your } \\
\text { organization. (Survey calendar) }\end{array}$ & none/some/most/all/don't know \\
\hline $\begin{array}{l}\text { Respondents can contact a help desk if they have } \\
\text { questions about a survey (e.g., a specific phone } \\
\text { number and/or e-mail address). (Help desk) }\end{array}$ & none/some/most/all/don't know \\
\hline $\begin{array}{l}\text { Respondents can find help on a website } \\
\text { (for example frequently asked questions). } \\
\text { (Website help) }\end{array}$ & none/some/most/all/don't know \\
\hline $\begin{array}{l}\text { Information is provided on the concrete use } \\
\text { of the statistical output based on the survey } \\
\text { request. (Concrete use) }\end{array}$ & none/some/most/all/don't know \\
\hline $\begin{array}{l}\text { Respondents can receive personalized } \\
\text { statistical feedback. (Feedback) }\end{array}$ & none/some/most/all/don't know \\
\hline $\begin{array}{l}\text { The contacts with large businesses are managed } \\
\text { by a single account manager. } \\
\text { (Account manager) }\end{array}$ & none/some/most/all/don't know \\
\hline
\end{tabular}

B5 Has your organization conducted any other activities to reduce response burden for business surveys? If so, please describe below.

Large memo field

B6 Can you help us find any recent (2005-2010) reports on how your institute aims to reduce businesses' response burden? We are particularly interested in any studies on the effects of these activities on response burden and data quality.

As an attachment to the invitation letter for this survey we included a list of papers we already found for your organization (if any).

Please enter any (other) references to reports below or send the reports to rbsurvey@cbs.nl or to Deirdre Giesen, Divison of Methodology and Quality, Room 1C33, PO Box 4481, $6401 \mathrm{CZ}$ Heerlen, The Netherlands.

B7a Have the above questions on response-burden reduction been answered by the same person who answered the questions on response-burden measurement?

Yes/no

\section{If No Then B7b}

Who answered the questions on response-burden reduction? 
Name:

---- Noempty

Function:

---- optional field

Specific domain of expertise:

-- - - optional field

Department:

---- optional field

E-mail:

---- Noempty, email check

Telephone number:

---- Noempty

B8a Who should we contact in your organization for additional information on response-burden reduction?

- same as person mentioned in previous question

- someone else

\section{If someone else Then B8b}

Please mention name, telephone number, e-mail address and, if applicable, specific domain of expertise of the person(s) we can contact for additional information on the reduction of response burden in your organization.

\section{Large memo field}

Closing message

\section{Appendix 3: Other Burden-reduction Actions Reported by NSIs Surveyed}

\section{Policies outside and within the NSIs}

- Better coordination across public agencies and authorities (3x)

- Seeking access to administrative data $(3 x)$

- Policy not to collect data if information is available in administrative data $(3 \mathrm{x})$

- Program of data collection split in two chapters, direct data collection and usages of administrative data from other government bodies (1x)

- Policy not to ask for the same information in different questionnaires (1x)

- 'No gold-plating' rule - implementing minimum requirements only $(2 \mathrm{x})$

- 'One-in, one-out' rule $(1 \mathrm{x})$

- Load Threshold Policy: proactive relief to businesses in accordance to size $(1 \mathrm{x})$

\section{Methods to make a questionnaire's completion easier}

- Regular monitoring/reviewing of questionnaires to detect problems of respondents $(3 \mathrm{x})$

- Testing usability of electronic web-based data collections $(1 \mathrm{x})$

- Offering questionnaires in multiple modes $(2 x)$

- Prefilling questionnaires with administrative data $(1 \mathrm{x})$

- Redesign of questionnaires to align them as far as possible with the Profit \& Loss and Balance Sheet account entries (1x)

- Establishment of Accounting Practices Unit that seeks to reconcile survey questions with business record keeping (1x)

- Establishment of response-improvement research staff to do research on questions $(1 \mathrm{x})$

- All questionnaires can be downloaded and sent back electronically through a public website $(1 \mathrm{x})$ 


\section{Actions to improve communication and relationship with respondents}

- Development of special shorter questionnaires for small businesses $(2 x)$

- Reduction of the level of detail asked on a number of questionnaires $(1 \mathrm{x})$

- Interaction between data collectors and respondents via ICT and Internet in order to complete questionnaires aiming at efficiency of the data-capture process $(1 \mathrm{x})$

- Website developed specifically for businesses, both as respondents and users $(1 \mathrm{x})$

- Accept a copy of the balance sheet of the annual account instead of filling in SBS questionnaire $(1 \mathrm{x})$

\section{Appendix 4: Clustering}

After testing various clustering methods, Ward's hierarchical clustering method was selected because it offered the most meaningful interpretations of the results obtained. Several permutations of unit ordering were compared in order to observe the effect of unit ordering on clustering results. At lower levels (with many small clusters) all results mostly matched. At higher levels, three main groups with some differences were mostly detected.

The best clustering result was identified based on the criterion-function value (the within sum of squares), some other theoretical measurements for cluster validationespecially the silhouette plot, the average silhouette width, and the height of aggregation in the hierarchical tree (Kaufman and Rousseeuw 1990; Everitt et al. 2001)-and cluster interpretability. The criterion-function values (the within sum of squares) ranged from 64.02083 to 75.45125 . The solution presented here, with three well-separated clusters, had the smallest obtained criterion-function value (64.02083) and offered a meaningful interpretation of the clusters. These clusters with 16, ten, and 15 NSIs can be seen clearly in the graphical presentation of the aggregation procedure (dendrogram) in Figure A1 (the plot was cropped at the bottom where NSI names appear for confidentiality reasons).

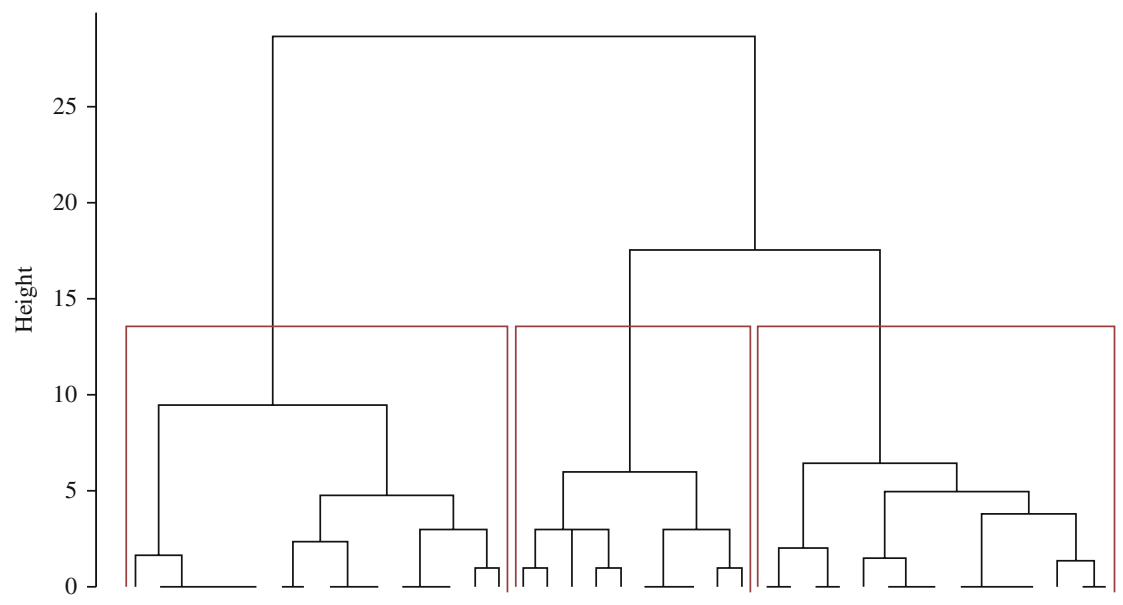

Fig. A1. Dendrogram of 41 NSIs, using six selected variables and obtained using Ward's hierarchical clustering method based on squared Euclidian distance for binary data. 
The silhouette plot shows how well each individual unit fits into the cluster. The silhouette plot and the values of the average silhouette width of the clusters in Figure A2 suggest that units fit somewhat better in the larger two clusters compared to the smallest cluster.

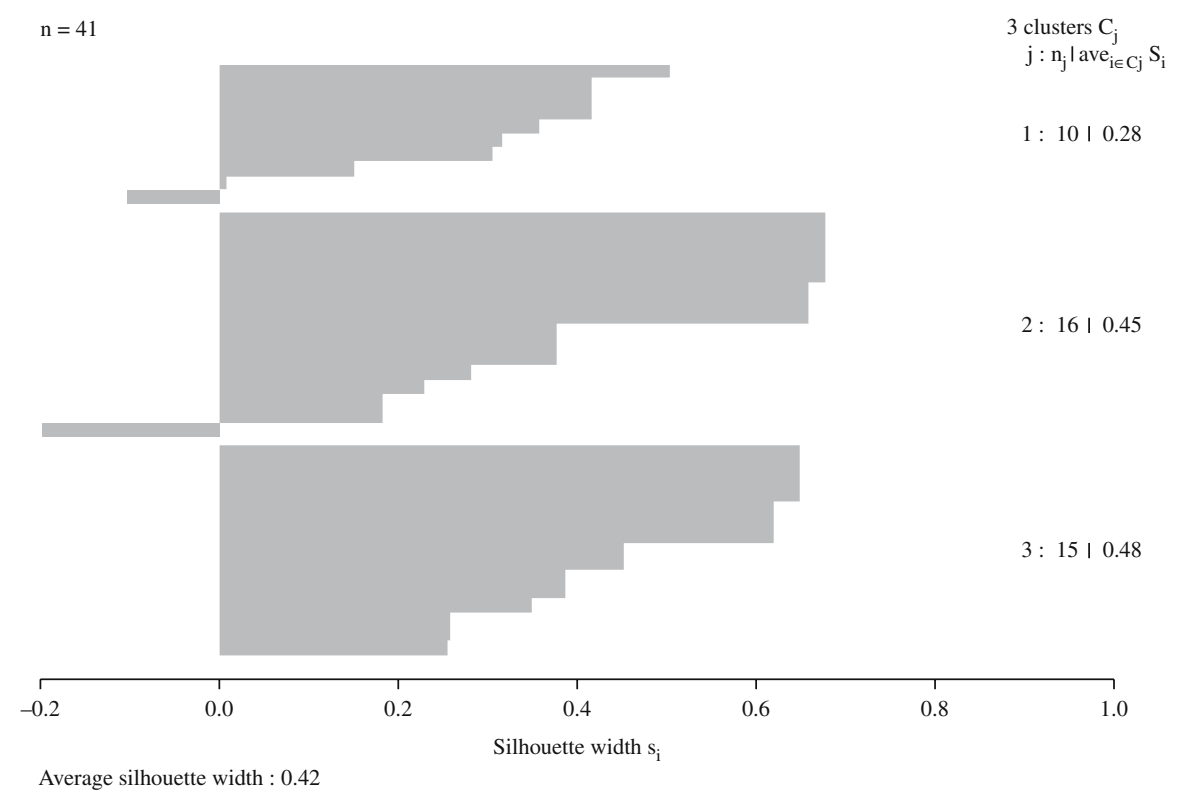

Fig. A2. Silhouette plot clustering 41 NSIs into three clusters.

\section{References}

Astin, J. 1994. "Statistical Form-Filling by Industry: Net Burden or Net Benefit?" International Statistical Review 62: 87-97. DOI: http://dx.doi.org/10.2307/1403547.

Bavdaž, M. 2010. "Sources of Measurement Errors in Business Surveys." Journal of Official Statistics 26: 24-42.

Berglund, F., G. Haraldsen, and O. Kleven. 2013. "Causes and Consequences of Actual and Perceived Response Burden Based on Norwegian Data." In Deliverable 8.1 of the BLUE-ETS Project, 29-35. Available at: http://www.blue-ets.istat.it/fileadmin/ deliverables/Deliverable8.1.pdf (accessed October 2014).

Central Statistics Office. 2012. Response Burden Barometer 2011. Measurement of Administrative Burden imposed on Irish Business by Central Statistics Offices Inquiries. Available at: http://www.cso.ie/en/media/csoie/releasespublications/documents/ multisectoral/2011/responseburden11.pdf (accessed April 2012).

Dale, T. and G. Haraldsen, eds. 2007. Handbook for Monitoring and Evaluating Business Survey Response Burdens. European Commission, Eurostat. Available at: http://epp. eurostat.ec.europa.eu/portal/page/portal/quality/documents/HANDBOOK\%20FOR\% 20MONITORING\%20AND\%20EVALUATING\%20BUSINESS\%20SURVEY\% 20R.pdf (accessed April 2013). 
European Commission. 2007. Action Programme for Reducing Administrative Burdens in the European Union. Communication from the Commission to the Council, the European Parliament, the European Economic and Social Committee and the Committee of the Regions. Brussels, January 24, 2007. Available at: http://eur-lex. europa.eu/LexUriServ/LexUriServ.do?uri=COM:2007:0023:FIN:EN:PDF (accessed April 2013).

European Commission. 2009. Reducing Administrative Burdens in the European Union - Annex to the 3rd Strategic Review on Better Regulation. Commission Working Document 16. Brussels, January 28, 2009. Available at: http://eur-lex.europa.eu/ LexUriServ/LexUriServ.do?uri=COM:2009:0016:FIN:en:PDF (accessed April 2013). European Commission. 2011. European Statistics Code of Practice for the National and Community Statistical Authorities. Adopted by the European Statistical System Committee, September 28, 2011. Available at: http://epp.eurostat.ec.europa.eu/cache/ ITY_OFFPUB/KS-32-11-955/EN/KS-32-11-955-EN.PDF (accessed April 2013).

European Commission. 2012a. Action Programme for Reducing Administrative Burdens in the EU Final Report. Strasbourg, December 12, 2012. Available at: http://ec.europa. eu/smart-regulation/refit/admin_burden/docs/com2012_746_swd_ap_en.pdf (accessed October 2014).

European Commission. 2012b. EU Regulatory Fitness. Communication from the Commission to the European Parliament, the Council, the European Economic and Social Committee and the Committee of the Regions. Strasbourg, December 12, 2012. Available at: http://ec.europa.eu/governance/better_regulation/documents/ 1_EN_ACT_part1_v8.pdf (accessed April 2013).

European Statistical System. 2012. Quality Assurance Framework of the European Statistical System. Version 1.1. Available at: http://epp.eurostat.ec.europa.eu/cache/ ITY_PUBLIC/QAF_2012/EN/QAF_2012-EN.PDF (accessed October 2014).

Eurostat. 2009. ESS Standard for Quality Reports. Eurostat Methodologies and Working Papers. Luxembourg: Office for Official Publications of the European Communities. Available at: http://epp.eurostat.ec.europa.eu/portal/page/portal/ver-1/quality/ documents/ESQR_FINAL.pdf (accessed April 2013).

Executive Order 13610 of May 10. 2012. Identifying and Reducing Regulatory Burdens. Federal Register Vol. 77, No. 93. Available at: http://www.whitehouse.gov/sites/ default/files/docs/microsites/omb/eo_13610_identifying_and_reducing_regulatory_ burdens.pdf (accessed April 2013).

Everitt, B.S., S. Landau, and M. Leese. 2001. Cluster Analysis, 4th ed. London: Edward Arnold Publishers.

Fröhlich, M., U. Oschischnig, and N. Rainer. 2012. "Meldepflichten und Belastung der Wirtschaft durch Erhebungen der Statistik Austria 2001-2011." Statistische Nachrichten 9: 729-741. Available at: http://www.statistik.at/web_de/statistiken/unternehmen_ arbeitsstaetten/respondentenbelastung/respondenten_belastungsbarometer/index.html (accessed April 2013).

Giesen, D., ed. 2011. Response Burden in Official Business Surveys: Measurement and Reduction Practices of National Statistical Institutes. Deliverable 2.2 of the BLUEETS Project. Available at: http://www.blue-ets.istat.it/fileadmin/deliverables/ Deliverable2.2.pdf (accessed April 2013). 
Giesen, D. 2012. "Exploring Causes and Effects of Perceived Response Burden." In Proceedings of the Fourth International Conference on Establishment Surveys: American Statistical Association, June 11-14, 2012, Montréal, Canada. Alexandria, VA: American Statistical Association. Available at: http://www.amstat.org/meetings/ ices/2012/papers/302171.pdf (accessed October 2014).

Giesen, D., G. Haraldsen, and M. Bavdaž. 2011. "Response Burden Measurement." In Deliverable 2.2 of the BLUE-ETS Project, 15-23. Available at: http://www.blue-ets. istat.it/fileadmin/deliverables/Deliverable2.2.pdf (accessed April 2013).

Giesen, D. and V. Raymond-Blaess, eds. 2011. Inventory of published research: Response burden measurement and reduction in official business statistics. A literature review of national statistical institutes' practices and experiences. Deliverable 2.1 of the BLUEETS Project. Available at: http://www.blue-ets.istat.it/fileadmin/deliverables/ Deliverable2.1.pdf (accessed April 2013).

Hak, T., D. Willimack, and A. Anderson. 2003. "Response Process and Burden in Establishment Surveys". In Proceedings of the Section on Government Statistics: American Statistical Association, August 3-7, 2003, San Francisco, 1724-1730. Alexandria, VA: American Statistical Association. Available at: http://www.amstat. org/sections/srms/proceedings/y2003/Files/JSM2003-000457.pdf (accessed April 2013).

Hedlin, D., T. Dale, G. Haraldsen, and J. Jones, eds. 2005. Developing Methods for Assessing Perceived Response Burden. Research report. Stockholm: Statistics Sweden, Oslo: Statistics Norway, and London: Office for National Statistics. Available at: http:// epp.eurostat.ec.europa.eu/portal/page/portal/quality/documents/DEVELOPING\%20 METHODS\%20FOR\%20ASSESSING\%20PERCEIVED\%20RESPONSE\%20BURD. pdf (accessed April 2013).

Hennig, C. 2014. fpc: Flexible procedures for clustering, R package version 2.1-9.

High Level Group of Independent Stakeholders on Administrative Burdens. 2009.

Subject: Priority Area Statistics. Available at: http://ec.europa.eu/smart-regulation/ refit/admin_burden/docs/enterprise/files/hlg_opinion_070709_statistics.pdf (accessed October 2014).

Hungarian Statistical Office. 2004. External Trade Statistics, Technical Implementation Report. Transitional Facility, 2004. Project No 6. Agreement No 19100.2005.0012005.532. Budapest: Department of External Trade Statistics. Unpublished document.

Jones, J. 2012. "Response Burden: Introductory Overview Lecture.” In Proceedings of the Fourth International Conference on Establishment Surveys: American Statistical Association, June 11-14, 2012, Montréal, Canada. Alexandria, VA: American Statistical Association. Available at: http://www.amstat.org/meetings/ices/2012/papers/ 302289.pdf (accessed April 2013).

Jones, J., J. Rushbrooke, G. Haraldsen, T. Dale, and D. Hedlin. 2005. “Conceptualising Total Business Survey Burden.” The Survey Methodology Bulletin 55: 1-10. Available at: http://www.ons.gov.uk/ons/guide-method/method-quality/survey-methodologybulletin/smb-55/index.html (accessed April 2013).

Kaufman, L. and P.J. Rousseeuw. 1990. Finding Groups in Data: An Introduction to Cluster Analysis. New York: Wiley. 
Lorenc, B., M. Bavdaž, D. Giesen, R. Seljak, and V. Torres van Grinsven. 2012. "Businesses as users of official statistics." In Proceedings of the Fourth International Conference on Establishment Surveys: American Statistical Association, June 11-14, 2012, Montréal, Canada. Alexandria, VA: American Statistical Association. Available at: http://www.amstat.org/meetings/ices/2012/papers/302173.pdf (accessed April 2013).

Lorenc, B, W. Kloek, L. Abrahamson, and S. Eckman. 2013. "An Analysis of Business Response Burden and Response Behaviour Using a Register of Data Provision." In Proceedings of the Conferences on New Techniques and Technologies for Statistics, March 5-7, 2013, Brussels. Available at: http://www.cros-portal.eu/content/ntts2013-proceedings (accessed April 2013).

Maechler, M., P. Rousseeuw, A. Struyf, M. Hubert, K. Hornik, M. Studer, and P. Roudier. 2014. Cluster: Cluster Analysis Basics and Extensions. R package version 1.15.3.

Merrington, R., B. Torrey, and L. van Heerden. 2009. "Measurement of Respondent Load at Statistics New Zealand." In Proceedings of the 57th session of the International Statistical Institute, August 16-22, 2009, Durban, South Africa. Available at: http:// www.statssa.gov.za/isi2009/ScientificProgramme/IPMS/0246.pdf (accessed April 2013).

Meyer, D., E. Dimitriadou, K. Hornik, A. Weingessel, F. Leisch, C.-C. Chang, and C.-C. Lin. 2014. e1071: Misc Functions of the Department of Statistics (e1071), TU Wien. R package version 1.6-4.

OECD. 2009. Mandate of the Regulatory Policy Committee. A New Agenda for the Regulatory Policy Committee: Issues for the Next Three years, 2010-12. Resolution of the Council concerning the Mandate of the Regulatory Policy Committee 11 December 2009. Available at: http://www.oecd.org/fr/gov/politique-reglementaire/44679685.pdf (accessed April 2013).

Office of Information and Regulatory Affairs. 2006. Questions and Answers when Designing Surveys for Information Collections. Washington: Office of Management and Budget. Available at: http://www.whitehouse.gov/sites/default/files/omb/assets/ omb/inforeg/pmc_survey_guidance_2006.pdf (accessed January 2013).

Ojo, O. E. and C. Ponikowski. 2010. "Evaluating the Effect of Dependent Sampling on National Compensation Survey Earnings Estimates." In Proceedings of the Section on Survey Research Methods: American Statistical Association. July 31-August 5, 2010 , Vancouver, British Colombia, 2766-2775. Alexandria, VA: American Statistical Association. Available at: https://www.amstat.org/sections/SRMS/Proceedings (accessed April 2013).

Paper Work Reduction Act of 1980, United States Federal Law. Title 44, Section 35, United States Code. Available at: http://www.archives.gov/federal-register/laws/ paperwork-reduction (accessed April 2013).

R Core Team. 2014. R: A Language and Environment for Statistical Computing (version 2.13.1). Vienna: R Foundation for Statistical Computing. Available at: http://www. R-project.org (accessed July 2011).

Red Tape Reduction Commission. 2012. Recommendations Report. Cutting Red Tape. Freeing Businesses to Grow. President of the Treasury Board, 2012. Available at: http:// www.reduceredtape.gc.ca/heard-entendu/rr/rr-eng.pdf (accessed April 2013). 
Sear, J. 2011. "Response Burden Measurement and Motivation at Statistics Canada." In Proceedings of the BLUE-ETS Conference on Burden and Motivation in Official Business Surveys, date of conference, 151-160. Heerlen: Statistics Netherlands. Available at: http://www.cbs.nl/NR/rdonlyres/23FD3DF5-6696-4A04-B8EF1FAACEAD995C/0/2011proceedingsblueets.pdf (accessed April 2013).

SCM Network. 2005. International Standard Cost Model Manual: Measuring and Reducing Administrative Burdens for Businesses. Available at: http://www. administrative-burdens.com/filesystem/2005/11/international_scm_manual_final_178. doc (accessed October 2014).

Statistics Belgium. 2010. "Administrative Simplification Structural Business Statistics Survey." In Proceedings of the SIMPLY 2010 Conference, December 2-3, 2010, Ghent. Available at: http://www.simply2010.be/documents/papers/SESSION_ 2b_P5_BE.doc (accessed April 2013).

Statistics New Zealand. 2008. Respondent Load Strategy for Statistics New Zealand: Strategies and Initiatives for Reducing Respondent Load. Wellington: Statistics New Zealand. Available at: http://www.stats.govt.nz/ /media/Statistics/about-us/ policies-protocols-guidelines/respondent-load-strategy/respondent_load_strategy.pdf (accessed April 2013).

Sunter, A. 1977. "Response Burden, Sample Rotation, and Classification Renewal in Economic Surveys.” International Statistical Review 45: 209-222. DOI: http://dx.doi. org/10.2307/1402535.

Triantafillou, P. 2007. "Benchmarking in the Public Sector: A Critical Conceptual Framework." Public Administration 85: 829-846. DOI: http://dx.doi.org/10.1111/j. 1467-9299.2007.00669.x.

United Nations. 1994. Fundamental Principles of Official Statistics. Available at: http:// unstats.un.org/unsd/dnss/gp/fp-english.pdf (accessed October 2014).

United Nations. 2014. Fundamental Principles of Official Statistics. Available at: http:// unstats.un.org/unsd/dnss/gp/FP-New-E.pdf (accessed October 2014).

Ward, J. H. 1963. "Hierarchical Grouping to Optimize an Objective Function." Journal of the American Statistical Association 58: 236-244.

Willeboordse, A. 1997. "Minimizing Response Burden." In Handbook on Design and Implementation of Business Surveys, edited by A. Willeboordse. 111-118. Luxembourg: Eurostat. Available at: http://ec.europa.eu/eurostat/ramon/statmanuals/ files/Handbook\%20on\%20surveys.pdf (accessed April 2013).

Received November 2013

Revised May 2015

Accepted May 2015 